\title{
A INCLUSÃO DA PESSOA COM DEFICIÊNCIA E O MULTICULTURALISMO: PELA CONSTRUÇÃO DE UM PAÍS MAIS SOLIDÁRIO
}

\author{
Ricardo Pinha Alonso ${ }^{1}$ \\ Lucas Emanuel Ricci Dantas ${ }^{2}$
}

\section{Resumo}

O presente artigo tem o objetivo de estudar a inclusão da pessoa com deficiência sob o viés do multiculturalismo, nesse viés busca-se evidenciar como deve-se projetar os direitos fundamentais dessa população, com vistas a formação de uma ética social que permita o respeito ao deficiente, e consequentemente garanta a efetividade de sua cidadania. Nesse interim, fomenta-se a criação de uma rede ágrafa, pautada em um agir comunicativo que tenha o intuito de incutir na sociedade a solidariedade entre os cidadãos propiciando uma sensibilidade para com as diferenças, e portanto com as deficiências. Referido estudo, foi feito com base em uma metodologia indutivabibliográfica.

Palavras-chaves: Pessoa com deficiência; ética; rede ágrafa; Kant;multiculturalismo.

\section{INTRODUÇÃO}

A pessoa com deficiência atualmente no Brasil, está protegida por uma série de leis e pelo Decreto Legislativo 186/08, que ratificou a Convenção Internacional de Direitos da Pessoa com Deficiência, incorporando-a no ordenamento jurídico nacional com força de direito constitucional. Referida convenção garante às pessoas com deficiência inúmeros direitos fundamentais, que por ora, ainda carecem de ser observados pela sociedade.

A tônica apresentada neste trabalho, busca demonstrar um componente ético que se apresente nos direitos fundamentais, que impõe à sociedade o respeito pelas pessoas com deficiência, e consequentemente a inclusão social. Neste aspecto procura-se evidenciar que é necessário a tomada de atitudes por parte do estado de incentivo de políticas públicas que propiciem a formação desta éticasocial.

\footnotetext{
1 Doutor em Direito do Estado - área de concentração Direito Constitucional, pela Pontifícia Universidade Católica de São Paulo (2012). Professor titular - Faculdades Integradas de Ourinhos e do Centro Universitário Eurípides de Marília. Coordenador da graduação e pós-graduação das Faculdades Integradas de Ourinhos. E-mail:ripiall@gmail.com

${ }^{2}$ Mestre em Teoria do Estado e Direito pelo Centro Universitário Eurípides Soares da Rocha - UNIVEM (2015), Advogado vol.09, nº. 02, Rio de Janeiro, 2016.pp. 1136-1154 1136
} 
formado pelo Centro Universitário Eurípides Soares da Rocha - UNIVEM (2013). Email para contato: lucas@lucasdantas.com 
Se utiliza como base para o estudo o conceito de multiculturalismo aliado à formação da rede ágrafa, entendendo-se que a deficiência é uma forma de cultura, por ser uma das múltiplas formas de vida existentes no meio social, ainda nesse viés sugestiona-se que a educação seria o meio para se fomentar a ética social da inclusão.

Através de uma metodologia indutiva bibliográfica, procura-se juntar conceitos que garantam uma sociedade inclusiva, com sensibilidade para diferenças, apta para receber o deficiente como cidadão em seumeio.

O objetivo de tal pesquisa, portanto se orienta na ideia de buscar respostas para concretização de uma sociedade com menos preconceitos, e que possa entender a deficiência de forma racional, permitindo assim a formação de um sociedade multicultural.

\section{A FORMAÇÃO DA REDE ÁGRAFA E A CONSTRUÇÃO DA CIDADANIA DA PESSOA COM DEFICIÊNCIA}

Para se falar em multiculturalismo, deve-se entender que, existe uma impregnação ética no estado de direito que leva à existência da alteridade inter-relacional de seus cidadãos, para que haja legitimidade nos direitos fundamentais a cada individuo isoladamente na sociedade. Nesse sentido, é obrigatório concordar com Habermas (2007, p. 98) expõe "A integração social depende amplamente de um agir que se oriente pelo acordo mutuo e que esteja embasado sobre o reconhecimento de reivindicações falíveis."

Tanto a inclusão como a integração da pessoa com deficiência, que aqui pode-se entender, que a segunda é uma evolução da primeira, tendo em vista, que a pessoa para ser integrada e participar da sociedade, precisa estar legitimamente incluída, sendo nesse sentido a exposição de Habermas quando entende que é necessário a aceitação da inclusão para ocorrer a integração. Não obstante a isso se torna necessária a integração para garantir validade à democracia, ou seja, ao estado democrático de direito. Por isso Habermas (2007, p. 135) continua explicando:

O estado constitucional democrático, de acordo com a ideia que o sustenta, é uma ordem desejada pelo próprio povo e legitimada pelo livre estabelecimento da vontade desse mesmo povo. Segundo Rosseau e Kant, os destinatários do direito também devem entender-se como seus próprios autores.

A perspectiva que se está utilizando é a de propor o respeito à pessoa com deficiência por meio de políticas públicas, que incentivem o respeito a esse contingente populacional. Para a pessoa com deficiência se entender autor da legislação inclusiva, esta precisa ter garantida a sua participação democrática na sociedade, sob pena de invalidar os preceitos constitucionais elencados como princípios e objetivos na Carta de 1988.

O Estado Brasileiro quando introduz em seu ordenamento uma constituição democrática, cria para si um componente ético e moral que deve ser introduzido no ambiente social, fazendo isso por meio dos direitos sociais, que inaugura o movimento denominado neoconstitucionalismo. Nesse ponto Jaborandi (2013, p. 82) explica: 
A introdução de direitos sociais nas constituições, aliada a incessante busca de efetividade dos direitos fundamentais, acelerou a consolidação do estado democrático de direito e contribuiu, sensivelmente, para o surgimento de um constitucionalismo contemporâneo, também denominado por muitos de neoconstitucionalismo.

O surgimento dos novos direitos, dos direitos difusos e coletivos, dos sujeitos específicos de direito, inaugura uma perspectiva de justiciabilidade de direitos na sociedade, que impõe atitudes éticas tanto do poder público quanto dos indivíduos que compõem a sociedade, criando uma esfera subjetiva dos direitos fundamentais.

A rede ágrafa de Habermas deve ser o objetivo das políticas públicas, com base na alteridade e no véu de ignorância de Rawls, onde se entende que sobre o véu de ignorância não há contingências que permitam discriminações, contudo, este não é o ponto fulcral do presente trabalho o qual pretende ficar restrito a filosofia habermasiana. Habermas (2007, p. 255) explica:

As pessoas a partir das quais em determinado momento se forma uma nação vinculada a um estado, no entanto, também corporificam a um só tempo as formas culturais de vida em que se formou sua própria identidade cultural - mesmo que nesse meio tempo ela já tenha se afastado das tradições de sua origem. As pessoas, ou melhor, as estruturas de personalidade formam como que junções dos fios de uma rede ágrafa de culturas e tradições de concatenações vitais e experiências intersubjetivamente partilhadas. (...)

Quando entende-se a deficiência como uma das muitas formas de vidas existentes na sociedade, deve-se entender então que a deficiência é uma forma de cultura e torna-se necessária a criação de uma rede ágrafa, onde a mistura dessas culturas resultará na inclusão das pessoas com e sem deficiência. Semelhantemente a essa idéia, muito longe de Habermas o Padre Antonio Vieira (1988) explicava em seu Sermão da Ephifania sobre a rede de pesca dos discípulos de Cristo, mostrando a semelhança dessa com a graça divina, sendo necessário que para participar da graça divina o homem precisa morrer para a vida pregressa, para nascer novamente assim como os peixes dentro de uma rede de pesca, o homem se debate para aceitar as imposições da religião.

A rede ágrafa não é diferente, dentro da rede ágrafa a sociedade precisa morrer para o preconceito e para a discriminação, com vistas a produzir alteridade. A razão comunicativa de Habermas é o meio de se produzir essa alteridade dentro da rede ágrafa, pois como o filósofo sustenta em outra obra, Habermas (2003, p. 156):

Uma vez que os sujeitos que agem comunicativamente se dispõe a ligar a coordenação de seus planos de ação ao consentimento apoiado nas tomadas de posição recíprocas em relação a pretensões de validade e no reconhecimento dessas pretensões, somente contam os argumentos que podem ser aceitos em comum pelos partidos participantes. São respectivamente os mesmo argumentos que tem uma força racionalmentemotivadora.

Dentro da rede ágrafa surgem argumentos racionais que garantem a inclusão das minorias, pois, ora que se entende o fator deficiência como um fator de cultura, é na rede ágrafa que essa cultura vai ser inclusa misturada as outras culturas e portanto integradas. Sendo que a Democracia só pode se efetivar para pessoas com deficiência se esta for aceita pela sociedade e conseguir alcançar participação e gozo dos seus direitosfundamentais. 
Por isso, Habermas (2003, p. 158) explica "a idéía básica é a seguinte o principio da democracia resulta da interligação que existe o principio do discurso e a forma jurídica." Se a forma jurídica é o direito codificado, ou seja, positivo, esse direito só terá validade no estado democrático caso haja o discurso, ou seja, a participação racional dos detentores desse direito. Portanto a política pública da inclusão da pessoa com deficiência abre a possibilidade de se discutir formas de efetividade de direitos fundamentais garantindo a participação democrática dessas pessoas na sociedade e consequentemente justiça social.

Por isso, o cidadão precisa se entender também como legislador para ter a garantia da validade de seus direitos fundamentais. Habermas (2003, p. 158) afirma "a idéia da autolegislação de cidadãos não pode, pois, ser deduzida da autolegislação moral de pessoas singulares. A autonomia tem que ser entendida de modo mais geral e neutro.". Notadamente deve existir um consenso para garantir o pertencimento da pessoa com deficiência na sociedade e a sua autonomia ser respeitada, não obstante a tudo isso começa se concluir que a rede ágrafa não pode entrar no coeficiente de inclusão como elemento, mas sim, como conseqüência da aplicação das políticas públicas inclusivas.

Pois, é pela rede ágrafa que os direitos fundamentais vão ter efetividade na sociedade para todos os cidadãos independente de suas características, visto que "as normas jurídicas não são surdas aos apelos da sociedade, ou seja, elas são também uma expressão de uma forma de vida particular, no caso o da sociedade na qual está inserida e não somente uma abstração neutra e universal dos direitos fundamentais." (Castro. 2009, p.4953).

Jaborandi (2013, p.93) comunga do mesmo entendimento:

(...) É da multiplicidade de opiniões e de interesses da sociedade que será elaborado o planejamento geral dos recursos públicos, direcionando os investimentos para setores priorizados pela própria comunidade. Somente assim será legitima a escolha pra construção de determinada política pública em detrimento de outra no estado democrático.

Neste aspecto, a política pública, só terá legitimidade caso, atenda o desejo da comunidade, então podese afirmar que a política pública de inclusão da pessoa com deficiência só tem legitimidade, se atender os desejos da parcela populacional que é deficiente e estiver circunscrita aos ditames das normas constitucionais e do Decreto Legislativo 186/08.

Diante disso importa observar também que, a política pública que atende o direito da pessoa com deficiência deve promover a inclusão e a integração dessa pessoa na sociedade, impondo à sociedade o dever de respeito para com a pessoa com deficiência. Por isso Cruz (2009, p. 103) afirma "Assim, a semiótica jurídica do direito à igualdade, ampliando seu campo de incidência e sua plurisignificação são indispensáveis sob a ótica da dignidade humana."

Nessa plurisignificação, incide a rede ágrafa de Habermas, como meio de existência da efetividade dos princípios constitucionais, e como fio condutor da ação comunicativa. Cruz (2009, p. 103) continua defendendo: vol.09, nº. 02, Rio de Janeiro, 2016.pp. 1136-1154 1140 
Uma sociedade calcada em tais princípios é, necessariamente, pluralista e inclusiva, pois deve garantir/estimular a participação de todos, aproveitando as diferentes cosmovisões e experiências humanas, reconhecendo/desenvolvendo o potencial de cada cidadão.

O reconhecimento da deficiência como uma das múltiplas formas de experiência de vida, deve estimular a convivencialidade das pessoas dentro do estado democrático superando o estigma da deficiência. A política pública funciona como incentivo para oferecer a possibilidade de uma nova conceituação sobre a pessoa com deficiência.

Habermas quando traz em seu Direito e Democracia (1993), a teoria da ação comunicativa, ela alcançara uma evolução em a inclusão do outro (2007) com a formação da rede ágrafa, deve se entender que o $\log o s$ da ação comunicativa, só pode se desenvolver no lócus da rede agrafa. Nesse sentido Habermas (2003, p. 191) “O poder comunicativo de convicções comuns só pode surgir de estruturas da intersubjetividade intacta.”

E mais à frente o mesmo autor assevera com rigor "o direito não regula com textos interacionais em geral, como é o caso da moral; mas serve como médium para a auto-organização das comunidades jurídicas que se afirmam, (...)” (Habermas. 2003, p. 191). A validade da norma jurídica se dá justamente quando o direito pode entrar na comunidade, no caso o Brasil, como um componente ético, que incorpora em seus cidadãos a responsabilidade co-participativa na garantia da efetividade dos direitosfundamentais.

A rede ágrafa deixa de ser utopia filosófica, quando entende-se que o direito é médium para a realização de uma norma moral, ou melhor, da criação de uma ética social. Nesse caso a sociedade vai entender que a inclusão da pessoa com deficiência é de responsabilidade do estado, mas também das pessoas sem deficiência, pois essas usufruem, na maioria das vezes da efetividade dos seus direitos fundamentais. Nessa senda Cruz (2009, p. 103) leciona:

A referida sociedade deve, assim, trabalhar no sentido de oferecer oportunidade para que cada cidadão possa ser respeitado, garantindo mecanismo para que o mesmo consiga integridade de sua autonomia autodeterminada e participativa. A ação comunicativa de um cidadão que é coautor das decisões políticas dá novo colorido a ideia de fraternidade do ideário da revolução francesa.

A preservação da autonomia da pessoa com deficiência, volta ao tema da efetividade do principio da dignidade humana, pois, na lição de Kant (1984), a dignidade só pode existir se reconhecida a autonomia de cada pessoa, donde se depreende que o médium do direito é indissociável da garantia de efetividade e respeito por parte do estado e da sociedade do principio da dignidade humana. A teoria discursiva de Habermas vem para complementar a tese de Kant sobre dignidade, onde esta só pode existir se houveraquela.

Nessa esteira de pensamento torna-se impossível existir política pública de inclusão sem se pensar na ação comunicativa dos cidadãos, a garantia da legitimidade do direito fundamental da pessoa com deficiência está adstrita a política pública, que consegue incorporar na sociedade uma éticainclusiva.

Apesar do conceito meramente teórico da rede ágrafa de Habermas, logo se entende que o objetivo a ser alcançado de uma sociedade que inclui a pessoa com deficiência, é a construção desta rede por meio de uma ética. vol.09, nº. 02, Rio de Janeiro, 2016.pp. 1136-1154 1141 
Entretanto resta saber quais são os meios que se darão a formação dessa rede, algo que passa-se a investigar nos próximos tópicos.

Ora, diante de toda a tônica que se está apresentando, deve-se ter em mente que a cidadania para a pessoa com deficiência só existe quando esta tem a possibilidade de participar comunicativamente dentro da sociedade. Podendo com tal possibilidade de comunicação gozar e representar os seus direitos, bem como, ter os mesmos representados.

\section{SER E DEVER-SER: O CONTEUDO ÉTICO DAS NORMAS DE INCLUSÃO SOCIAL}

Tomando por base, a norma de direito fundamental, e o seu desdobramento entre o ser (Sein) e deverser (Sollen), pode-se entender os aspectos contidos nas relações de direito propostas por Alexy(2011) estado/cidadão e cidadão/cidadão. Sendo de relevância para o estudo da inclusão da pessoa com deficiência a relação cidadão/cidadão, na busca de como esta acoimada á norma de direito fundamental vai se concretizar dentro da rede ágrafa, Telles Júnior (2011, p. 207) explica "A lei, bem o sabemos é um imperativo, mandamento, mas não é um mandamento qualquer". Esse mandamento diferenciado vai se coadunar com a realidade social do país, pois continua explicando o professor (2009, p.207):

É um imperativo normativo e isso quer dizer que a norma verdadeiramente jurídica é sempre um mandamento harmonizado com a normalidade, com a ordenação de uma coletividade humana. Por ser norma, a lei há de ser congruente com a normalidade ambiente.(...)

A grande dificuldade de se estabelecer um estudo jurídico da inclusão da pessoa com deficiência, é que este não vai avaliar norma a ser feita ou criada mas vai adequar a norma existente à realidade ambiente, e nesse aspecto pode-se encontrar um vazio de efetividade, no qual a hermenêutica tradicional não preencherá.

Surge uma grande diferenciação aqui, do estudo da filosofia prática, tornando-se necessário o estudo da ontologia do ser. Como seleciona Engelmann (2009, p. 85) "O conceito de ser também traz um outro aspecto bastante peculiar, ao enfatizar a possibilidade da “coisas em si” em contraposição ao fenômeno.". Para ser estudado o ser ( sein) dentro de uma perspectiva de Habermas e da teoria da comunicação, é urgente o reestudo do ente na visão pós Kantiana, se utilizando de Kant apenas no tocante ao imperativo categórico em um tópico à parte.

A existência do ser e do dever ser, é a partícula de adequação da Constituição com a realidade, por isso concorda-se com Hesse (2002, p. 6) que afirma "As possibilidades, mas também os limites da força normativa da Constituição resultam da correlação entre ser (sein) e dever-ser (solein)." A correlação do ser com o dever ser, necessita do dasein para garantir a efetividade do direito na sociedade.

Um sistema social, como a rede ágrafa de Habermas, ora aqui defendido, só pode existir se o dasein o "ser-o-aí" estiver presente no meio social, ou melhor nos filões de junção desta rede. Esse expressão de "ser-o-ai" que compreende o dasein vem de Heidegger, e pode ser explicado por Giacoia Junior (2013, p. 67): 
Ser-o-aí é o que nos é mais próximo, já que somos nos mesmos que existimos como tal. Porém, do ponto de vista ontológico é o que há de mais de estranho e distante para nós, Quanto ao conhecimento de nossa essência. Para nos aproximarmos reflexivamente desse conhecimento, temos de perguntar pelo modo de ser da existência que somos. Esta é, fundamentalmente contingência, temporalidade, facticidade, (faktizitat), finitude.

A operação efetiva que deve ser realizada na norma para garantir validade e efetividade deve resultar do compromisso temporal da sociedade com a norma, neste ato também a norma deve corresponder ao querer da sociedade, sob pena de ser ilegítimo. Por conseguinte a inclusão da pessoa com deficiência só pode ser realizada, caso a sociedade se comprometa com a inclusão e encontre em seu ser a pessoa com deficiência, libertando um querer da inclusão pois compreende a necessidade desta.

Neste aspecto Giacoia Junior (2013, p. 73) continualecionando:

(...) engajamo-nos com certos entes em um relacionamento que não é nem o de cognição nem o de lida prático-instrumental, mas uma relação pessoal, ética. Essa relação não se limita à que estabelecemos com os outros, mas esta também ontologicamente vinculada a relação que criamos conosco, a um tipo originário de cuidado de si, de préstimo e cura das possibilidades sempre abertas que constituem nossa existência.

Não obstante a tudo isso o Professor Telles Junior, com influência premente heiddegeriana, vai concordar com a possibilidade fática de adequação das normas com a realidade social, por isso vai defender que vários fatores como dados sociais, contingências históricas, as contradições entre o dever e o comportamento, "é o que constitui o manancial de onde brotam normas originais de convivência, originais entendo de ordenação, as vezes usos e costumes que irão inspirar a obra do legislador.” (Telles Junior. 2011, p.206)

Ocorre que a hermenêutica se inverte, ao passo que a obra legislativa já esta pronta, ou seja a Constituição e os direitos da pessoa com deficiência, elencados no Decreto Legislativo 186/08, entretanto apesar de pronta a obra legislativa carece de efetividade social.

A possibilidade do ser-o-aí, é a ideia da garantia da solidariedade social, princípio da carta constitucional de 1988 e fundamento básico da garantia do acesso a democracia por todos os cidadãos, independente de suas contingências pessoais. "Enquanto principio social, a solidariedade implica ação de todos em favor do bem comum, isto é, o empenho de todos para que todos e cada um realizem sua dignidade." (Lorenzo. 2010, p. 132)

Esse empenho social, só pode existir caso haja a relação ontológica de reconhecimento do ser, que sustenta Heiddeger, todavia é ponto fundamental a solidariedade para a existência da alteridade, ora as políticas publicas que concretizam os direitos fundamentais elencados nas normas constitucionais não deveriam buscar esse objetivo? A pergunta é retórica pois o objetivo da comunhão social já é elencado na sociedade democrática, quando a Magna Carta seleciona igualdade, fraternidade e solidariedade como princípios chaves da sociedade.

"Como afirma Edith Stein, a solidariedade demonstra que o individuo é uma abstração, e que o ser humano é um devedor constante do seu meio." (Lorenzo. 2010, p. 132). A realização do coeficiente só pode acontecer se a norma for o objetivo de integrar a sociedade com a comunidade a que a norma se destina. Nesse 
sentido os cidadãos começarão existir uns com os outros, pois "Existir significa, em sentido radical, cuidar de poder ser no mundo, que é também (e não menos essencialmente) ser-com-os-outros." (Giacoia Junior. 2013, p.74).

O daisein de Heddeiger, complementa assim a norma, tendo em vista que o dever-ser não é apenas um mandamento, mas também uma possibilidade de coexistir no mundo. Por isso Engelmann (2009, p. 93-94) explica:

A concepção heiddeigeriana de mundo aborda a ideia do "ser-no-mundo" e do "ser-com-omundo", ou seja, deixa transparecer que o ser do ente desenvolve as suas qualidades de percepção e criação no mundo; ao mesmo tempo também se desenvolve concomitantemente com o aprimoramento do próprio mundo, como um espaço privilegiado para o aumento das faculdades humanas finitas. Vale dizer, não há homens, porque existe mundo, mas há mundo porque existem homens.

Essa força impulsionadora de criação possibilitada, pelo homem no mundo é o que dá origem ao que Habermas chama de multiculturalismo, a criação do mundo pela percepção humana se forma através de várias culturas, que devem estar entrelaçadas e em harmonia, possibilitando o alinhamento da sociedade com a norma constitucional, "Pois se a existência dos objetos é o ser, a existência da pessoa é o viver." (Lorenzo.2010, p. 53)

A deficiência nesse aspecto, aqui aparece sendo sinônimo de cultura e de multiplicidade de formas de vida. Por isso torna-se de suma importância entender o multiculturalismo como uma forma de inclusão das minorias com a maioria, dando origem consequentemente à participação democrática de todos no estado constitucional, objeto de estudo que aborda-se no próximo tópico.

\section{MULTICULTURALISMO: O OBJETIVO DEVE SER ALCANÇADO PELA PARTICIPAÇÃO DEMOCRÁTICA DA PESSOA COM DEFICIÊNCIA NA SOCIEDADE}

Dentro do que vem sendo falado, quando o cidadão consegue perceber a dificuldade do outro cidadão e se comprometer com a legitimidade do seu direito e do direito do outro, isso dá origem ao que Habermas chama de multiculturalismo. Esse multiculturalismo seria a mistura de culturas heterogêneas, originando uma cultura homogênea, obviamente que pensando na estrutura do estado democrático de direito.

Nessas sociedades contemporâneas surgem problemas de origem hierárquica, quando uma determinada "cultura" nega os direitos de outra "cultura", por aquela ser maioria em relação a esta. Habermas (2007. p. 170) defende:

A leitura liberalista da autodeterminação democrática mascara, contudo o problema das minorias "inatas", que é percebido com maior clareza a partir do ponto de vista comunitarista, assim como do ponto de vista intersubjetivista da teoria do discurso. $\mathrm{O}$ problema também surge em sociedades democráticas, quando uma cultura majoritária, no exercício do poder político impinge as minorias a sua forma de vida, legando assim ao cidadão de origem cultural diversa uma efetiva igualdade de direito. 
Partindo do pressuposto que a deficiência é uma forma diversa de cultura, como ora aqui se defende, deve-se buscar então soluções que garantam a efetividade total dos direitos de cada cidadão com deficiência, aqui se esbarra na suposta falta de reconhecimento pelo estado brasileiro da pessoa com deficiência.

Por isso o direito interfere em questões éticos políticas e essas intervenções originam uma mudança estrutural da vida de cada cidadão. Nesse aspecto Habermas (2007, p. 171) leciona "Na medida em que o direito intervém em questões ético-políticas, ele toca a integridade das formas de vida dentro das quais está enfronhada a configuração pessoal de cada vida."

$\mathrm{Na}$ formação de uma sociedade multicultural, as questões éticas do direito podem-se formar de uma maneira universal, devido à mistura da culturalidade de cada cidadão. Por isso defende-se que o multiculturalismo é a forma de configuração social que se dá a partir da rede ágrafa, e é dentro dessa configuração que o direito pode ser perceptível e legítimo, pois, todos irão cobrar mutuamente os direitos elencados na constituição. Ora não é essa a ideia da Constituição Federal de 1988? Não é esse o pilar basilar da sociedade democrática? Para melhor entendimento do assunto cita-se Habermas (2007, p. 171):

Uma nação de cidadãos é composta de pessoas que, devido a seus processos sociais, encaram simultaneamente as formas de vida dentro das quais se desenvolveu sua identidade - e isso ocorre mesmo quando, como adultos, eles se libertaram das tradições de sua origem. Naquilo que é relevante para seu caráter, as pessoas são como entroncamentos numa rede adscriticia de culturas e tradições.

Nesse aspecto, o autor ainda defende "O multiculturalismo ao mesmo tempo que apoia a perpetuação de vários grupos culturais dentro de uma sociedade política, também requer a existência de uma cultura comum ..." (Habermas. 2007, p. 173). A concepção multicultural da sociedade leva a contornos políticos comuns de todos os cidadãos, consequentemente esses contornos se valem da necessidade de posturas éticas iguais por meio dos atores sociais.

A teoria do discurso garante o entendimento do direito por todos dentro do estado, tendo por resultado a possibilidade de questionamento das normas postas pelo poder político. A legitimidade do direito, só pode ser encarada quando garante a autonomia de seus cidadãos como auto legisladores, logo se tem que "Uma ordem jurídica é legitima quando assegura por igual a autonomia de todo cidadão. E os cidadãos só são autônomos quando os destinatários do direito podem ao mesmo tempo entender-se a si mesmos como autores do direito. (Habermas. 2007, p. 250)

Ressalta-se então que, a autonomia da pessoa com deficiência só pode ser garantida quando esta puder se posicionar como destinatária e autora dos seus direitos, mas também, quando os demais cidadãos puderem reconhecer a deficiência como um critério especifico do sujeito de direito. Nesse diapasão a sociedade multicultural entra como resultado das políticas públicas que pretendem efetivar os direitos fundamentais dos 
deficientes. Ressalta-se que, para realização dessa multicuturalidade é necessário a conscientização social da existência da deficiência, pelos demais cidadãos da sociedade, algo que se busca naeducação.

\section{PEDAGOGIA E DIREITOS HUMANOS: O GRANDE PASSO DA INCLUSÃO SOCIAL}

Dentro do tema que está sendo abordado, incumbe avaliar como se dá a relação ética dos direitos humanos na sociedade, e como se construirá o reconhecimento das pessoas com deficiência pelos demais indivíduos que compõe o estado democrático de direito. Ora, o que se defende é que os direitos humanos tenham uma função pedagógica, sendo necessário para conclusão das políticas públicas que estão acoimadas neles, uma instrução pedagógica, para garantir sua efetividade além dos fóruns etribunais.

Logo se vê, que é necessário conhecer o direito do outro e o direito individual, para poder respeitar a implantação de tais direitos na sociedade, a alteridade, que propicia esse reconhecimento necessita do auxílio pedagógico para inferir na estrutura do conhecimento individual e propiciar uma ética coletiva. Nesse sentido Comparato (2010, p. 71) explica com precisão:

Sem duvida, o reconhecimento oficial de direitos humanos, dá muito mais segurança as relações sociais. Ele exerce também, uma função pedagógica no seio da comunidade, no sentido de fazer prevalecer os grandes valores éticos, os quais, sem esse reconhecimento oficial, tardariam a se impor na vida coletiva.

Notadamente, tanto a formação da rede ágrafa quanto a formação do multiculturalismo, necessita de uma formação pedagógica que valorize a formação ética dos cidadãos, enquanto educandos, para propiciar a formação de uma sociedade solidária e não discriminativa. O linear pedagógico que se requer dos direitos humanos, é algo libertador, que desvele o mundo, e insira o cidadão na realidade social não contingente. Por isso Freire (2001, p. 36) explica “A educação consegue dar as pessoas maior clareza para "lerem” o mundo", e essa clareza abre a possibilidade de intervenção política."

É por meio da educação que a pessoa com deficiência vai requerer os seus direitos perante o estado democrático, e também é por meio da educação aliada às políticas públicas que a pessoa sem deficiência, vai reconhecer que o deficiente tem direitos e respeitá-lo em sua dignidade. Freire (2001, p. 36) continua explicando "A pratica educacional não é o único caminho à transformação social necessária à conquista dos direitos humanos, contudo acredito que, sem ela, jamais haverá transformaçãosocial."

Portanto, só pela educação que se formará alteridade dentro do meio social, observa-se que se a pratica educacional é um meio de transformação social. É também por meio dela que se encontrará o objetivo buscado pela inclusão da pessoa com deficiência, pois, não há como ser de outra maneira que o individuo sem deficiência reconheça o seu par.

Se requer que haja uma profunda transformação social, possibilitando a inclusão e o acesso da pessoa com deficiência, aos bens juridicamente tutelados constitucionalmente. Ocorre que a pessoa com deficiência só vol.09, nº. 02, Rio de Janeiro, 2016.pp. 1136-1154 1146 
pode ter acesso ao bem, se a sociedade tanto como estado, quanto como meio social reconhecer a dignidade dentro da deficiência. Objetiva-se um conhecimento relacional entre as pessoas por meio da educação, nesse aspecto Freire explica (2001, p. 53):

Também acredito na força das verdadeiras relações entre as pessoas para a soma de esforços no sentido da reinvenção das gentes e do mundo. E não há como negar que a experiência dessas gentes envolve, de um lado, a curiosidade humana, centrada na própria prática relacional, de outro, a curiosidade alongando-se a outros campos. $\mathrm{O}$ envolvimento necessário da curiosidade humana gera, indiscutivelmente, achados que, no fundo, são ora objetos cognoscíveis em processos de desvelamento, ora o próprio processo relacional, que abre possibilidades aos sujeitos da relação da produção deinter-conhecimentos.

Esse inter-conhecimento só pode ser gerado dentro de uma sociedade multicultural, ou nas palavras de Habermas, com sensibilidade para diferenças. A pedagogia auxilia na criação de conceitos e fomenta o conhecimento da deficiência por educandos não deficientes, aqui não se fomenta que a pedagogia é a única política pública existente para inclusão da pessoa com deficiência, pelo contrário uma boa política pública pedagógica que incentive a não discriminação, auxilia nas políticas públicas que incentivam o convíviosocial.

Ora, o cidadão só pode se conceber numa sociedade multicultural, quando entende, quando é ensinado da existência de diversas culturas, e a partir disso se coloca como agente de mudança social buscando a concretização do bem comum na coletividade. Por isso Padilha (2011, p. 176) defende "A multiculturalidade é criação histórica e, como tal, exige de todos nós o estabelecimento democrático e coletivo de fins comuns para uma convivência ética."

Uma convivência ética portanto está ligada indiscutivelmente à democracia e também, à concretização de fins coletivos comuns, ora, é lógico que o direito entra por meio da teoria do discurso como mediador dessa ética convivêncial, buscando promover a pessoa humana acima de todas as coisas dentro da sociedade, desenvolvendo por meio de políticas públicas formas que eliminem qualquer condição de exclusão social. Nesse aspecto Padilha (2011, p. 175-176) explica:

O homem não é o ser da guerra, mas do amor, da afetividade, da esperança e da utopia. Falta lhe a abertura para aprender com a diversidade e buscar uma sociedade que consiga alcançar uma ética fundada no respeito às diferenças, isso significando conviver com elas e não se isolar nos guetos multiculturais que não enfrentam os desafios de uma radicalidade democrática para a convivência plena de direitos e deveres.

A inserção do cidadão a partir de sua inteligibilidade em uma sociedade multicultural, demonstra uma abertura bilateral para inclusão social da pessoa com deficiência, sendo a do não deficiente em reconhecer a necessidade de buscar e promover uma sociedade igualitária, portanto inclusiva. E a da pessoa com deficiência de ter um estímulo a buscar o seu espaço dentro do meiosocial.

Aqui, pode se vislumbrar que tanto a política pública pedagógica, quanto a política pública de incentivo ao convívio social, como por exemplo, a praça paradesportiva do município de Bauru, e os jardins sensoriais do município de São Paulo, espaços públicos que permitem a convivência de pessoas com e sem deficiência, entre 
outras políticas públicas de inclusão que tem o cunho de propiciar a formação do conhecimento dos direitos fundamentais da pessoa com deficiência pelos demais cidadãos. Nesse aspecto torna-se importante, trazer o conceito de Telles Junior (1988, p. 189) sobre conhecimento:

$\mathrm{O}$ conhecimento resulta da ação das cousas, que fornece à inteligência os primeiros e indispensáveis elementos, e da ação da inteligência, que forma imagens e que, dessas imagens, abstrai o que nelas há de inteligível - o que nelas estiver em condições de ser apreendido pela inteligência -, ou seja, a essência das cousas.

A pedagogia não é apenas uma política pública de auxílio as políticas públicas de incentivo à convivência, mas também é o objetivo fim dessas, quando colocadas em prática no meio social, com vistas à transformação da consciência do cidadão e da implantação de direitos constitucionalmente estabelecidos.

Quando a pessoa com deficiência busca o seu espaço na sociedade, a mesma afirma sua dignidade e efetiva os princípios do estado democrático de direito, ainda que pese, que nem todos os direitos fundamentais desta tenham efetividade, surge a possibilidade destes virem a ter pela participação democrática.

Concretiza-se o esforço social para realização do bem comum, onde objetiva-se a realização do bem comum, que é buscado por todos cidadãos quando os mesmo compreendem a existência do direito e da dignidade do outro ser humano independente desse outro ser deficiente ou não. Por isso, Lorenzo (2010, p. 71) defende:

Só a partir da pessoa humana o bem comum torna-se inteligível. Se para o Estado ele é fim, em relação a pessoa ele é um meio privilegiado de seu aperfeiçoamento e requer a realização de direitos e deveres sem os quais a dignidade da pessoa tornar-se-ia mera alegoria. Assim, não há de se afirmar uma plenitude humana isolada, a despeito da sociedade ou mesmo do corpo público. Sem o bem comum a plenitude humana tornar-se-ia uma fábula, umautopia.

A noção do bem comum integra a perspectiva dos direitos humanos e fundamentais dentro do estado democrático de direito. Pois bem, esta noção complementa a ideia da inclusão, tendo em vista que reconhece a necessidade de um espaço público, ou seja, de um espaço dentro do estado comum a todas as pessoas, onde possa fruir todos os direitos fundamentais. Nesse aspecto, "O bem comum não exige que os membros de uma comunidade tenham os mesmos valores e objetivos, ele é o lugar comum de bens próprios da natureza humana, bens individuais comuns a todas as pessoas" (Lorenzo. 2010, p.71)

Vislumbra-se aqui a possibilidade da realização pessoal, conferindo dignidade à pessoa humana, consequentemente ao deficiente, através de uma interação entre o cidadão e a sociedade, com o objetivo de possibilitar um "consenso ético" no qual os cidadãos buscam a efetividade plena dos direitos fundamentais individuais e coletivos, com o propósito de exercer a plenitude de sua dignidade e autonomia. O Professor Lorenzo (2010, p. 72) continua explanando com precisão:

Essa relação entre o bem individual e o bem comum é regida por um princípio secundário que Karol Wojtyla denomina principio de correlação entre o bem da pessoa e o bem comum, segundo o qual se constata que a natureza social da pessoa a leva não apenas a interagir com seres humanos, mas the confere uma inclinação interior à criação de sociedades e comunidades, pois, ainda que faça parte de uma espécie, o individuo humano é vol.09, nº. 02, Rio de Janeiro, 2016. pp. 1136-1154 1148 
uma pessoa e sua espécie não é uma multidão caótica, mas formada, por sua própria natureza, por sociedades e comunidades. (...)

A função pedagógica, que aqui quer se defender, reside justamente na capacidade do ser humano de se inclinar à formação de uma comunidade, ou melhor, de um lugar comum, o multiculturalismo tem essa ideia na sua gênese, ou seja, a mistura de culturas para propiciar a igualdade entre os concidadãos. Logo se vê que o princípio da correlação pode se colocar dentro da alteridade, sendo esta somada aquele a possibilidade da realização de uma sociedade permeada de virtudes e não de vícios. A inclusão da pessoa com deficiência depende fulcralmente do desenvolvimento de uma sociedade virtuosa, do desenvolvimento da ética da alteridade e da pedagogia trazendo para o ser a possibilidade de repensar conceitos sociais.

Aqui se vislumbra que a pedagogia aplicada aos direitos humanos, mais especificamente à pessoa com deficiência, não é apenas mera questão epistemológica e sim uma questão ontológica de possibilidade do reconhecimento do ser e da interação de um ser com todos os seres. Por isso Lorenzo (2010, p. 73) explica "A vida humana em si não é objeto de um direito, mas o próprio sujeito é fundamento de todos os direitos."

Se a vida é fundamento de todos os direitos, à inclusão torna-se fundamento único de todos os direitos, por meio de uma lógica preponderante, que garante a pessoa com deficiência a possibilidade de gozar a vida dentro do estado democrático, dentro do espaço jurídico das normas vigentes. Ora, a efetividade da inclusão ligase à efetividade da vida, pois, estão as duas umbilicalmente entrelaçadas na perspectiva de preservação e garantia do princípio fundamental da dignidade da pessoa humana.

Portanto a realização do bem comum impende em uma atividade do estado, que possa formar a ética relacional, convivencial, de alteridade, por ora não pretende-se avaliar a inclusão sobre a ótica de Paulo Freire, na obra A Pedagogia do Oprimido, algo que se fará extensamente no próximo capitulo. Entretanto, necessário se mostra entender que a pedagogia é um caminho de efetividade para os direitos humanos e fundamentais da pessoa com deficiência, sendo ela também um elemento fulcral de implantação da sociedade multicultural.

Ocorre que tal ética da convivência, mesmo se efetivando dentro de uma teoria discursiva habermasiana, necessita ser regida por imperativos kantianos, mais especificamente o imperativo categórico que será o objeto de estudo seguinte.

\section{ÉTICA KANTIANA EM FAVOR DA PEDAGOGIA DOS DIREITOS HUMANOS}

Uma ética da alteridade, como vem se pautando dentro deste trabalho, impende a necessidade de ser estudado o imperativo categórico e a moralidade dentro das propostas trazidas por Kant. Notadamente se evidencia a inclusão como algo bom e que deve ser desejado pela sociedade, a inclusão da pessoa com deficiência deve residir numa boa vontade da sociedade em querer tal objetivo. Kant (1997, p. 23) explica: 
A boa vontade não é boa por aquilo que promove ou realiza, pela aptidão para alcançar qualquer finalidade proposta, mas tão-somente pelo querer, isto é, em si mesma, e, considerada em si mesma, deve ser avaliada em grau muito mais alto do que tudo o que por seu intermédio possa ser alcançado em proveito de qualquer inclinação, ou mesmo, se se quiser, da soma de todas as inclinações (...)

A boa vontade em Kant, reside em algo desvinculado de qualquer interesse, e assim Kant propõe a existência do imperativo categórico, nesse caso pode-se dizer que a inclusão da pessoa com deficiência não tem nenhum aspecto moral, e sim é apenas uma ação boa, e necessária existente da boa vontade dos cidadãos que vivem em uma sociedade igualitária. Sandel (2013, p. 147) explica "O que importa, segundo Kant, é que a boa ação seja feita por ser a coisa certa - quer isso nos de prazer, quernão.”

A inclusão da pessoa com deficiência, é a coisa certa, pois é, um direito consagrado constitucionalmente e portanto fundamental da pessoa que afirma a sua dignidade dentro do estado, nesse caso a ação pedagógica dos direitos humanos vai favorecer a construção de uma sociedade regida por imperativos kantianos. Segundo Kant (1997, p. 48) "A representação de um principio objectivo, enquanto obrigante para uma vontade, chama se um mandamento (da razão), e a formula do mandamento chama-se imperativo.

Continua o autor explicando Kant (2007, p.48):

Todos os imperativos se exprimem pelo verbo dever (solein), e mostram assim a relação de uma lei objectiva da razão para uma vontade que segundo a sua constituição subjectiva não é por ela necessariamente determinada (uma obrigação).(...)

O que pode-se denotar é que sempre que há uma relação social, que tem um direito fundamental por trás, tem-se também a existência de um imperativo kantiano, tendo em vista existência do verbo (solein). Entretanto dentro dos quatro imperativos propostos por Kant, o que interessa ou objeto de estudo trabalhado é o categórico, pois como preleciona o próprio Kant (1997, p.50):

O imperativo categórico, que declara a acção como objectivamente necessária por si, independente de qualquer intenção, quer dizer sem qualquer outra finalidade, vale como principio apodíctico (prático).

O imperativo categórico é o que vai fornecer a possibilidade de atitudes práticas, sem a necessidade de incentivos, ou interesses contingentes dentro da ação individual de cada pessoa. Se a alteridade é o enxergar do outro em si mesmo, uma ética da alteridade é pautada no imperativo categórico pois, não vamos querer para o outro o que não queremos para nós mesmos.

A dinâmica do imperativo categórico, propõe o reconhecimento da dignidade intrínseca à pessoa humana e fomenta uma ação tratando as pessoas como fins e não meios, determinando uma ação autônoma focada na liberdade individual de cada um. Caso contrário as nossas ações seriam heteronímicas, não permitindo a construção de uma sociedade multicultural, Sandel (2013, p. 142) explica com precisão "Quando agimos de maneira heteronímica, agimos em função de finalidades externas. Nós somos os instrumentos, e não os autores, dos objetivos que tentamos alcançar." 
Nesse diapasão, urge a necessidade de se pensar na ação de forma autônoma e considerar a dignidade da pessoa humana como fim em si mesmo, sob pena de não gozar do caráter emancipatório existente nos direitos fundamentais. Portanto verifica-se a necessidade de reconhecer a dignidade da pessoa com deficiência em qualquer circunstância, tendo em vista que a dignidade é um valor absoluto do estado e a inclusão com o reforço subsequente desta é um direito fundamental e constitucional da pessoa com deficiência. Nesse sentido tem se que a inclusão é um direito categórico, revelando a sua incondicionalidade para existir, ou seja, independente de qualquer contingência, a inclusão deve existir.

Nesta senda, concorda-se com Sandel (2013, p. 151), que fazendo alusão ao imperativo categórico diz "Da mesma forma, um dever ou um direito categórico é aquele que deve prevalecer em quaisquer circunstância.".

A construção do imperativo categórico está arrimada na lei universal, ou seja, "o imperativo categórico é portanto só umúnico que é este: age apenas segundo uma máxima tal que possas ao mesmo tempo querer que ela se torne lei universal." (Kant. 1997, p. 59). Querer a inclusão é se entender como deficiente na sociedade e buscar a efetividade dos direitos fundamentais da pessoa com deficiência, pois o cidadão reconhece que se fosse deficiente, também iria querer os mesmos direitos. Sandel (2013, p. 152) explica "O que há de essencialmente positivo na ação é a disposição mental, quaisquer que sejam as consequências."

A pedagogia, entra como auxílio no alcance do imperativo categórico, ainda que tal imperativo não possa ser reconhecido epistemologicamente ou medido cientificamente, entretanto a busca por ele se torna meio indissociável para concretização de uma sociedade multicultural e inclusiva. $\mathrm{O}$ imperativo categórico não fica preso à regra de ouro, porém vai além dela, pois reconhece a dignidade como o fim da pessoa humana e determina o respeito a todos os seres independentemente de qualquer situação individual, concordamos com Sandel (2013, p. 157) que explica "O imperativo categórico obriga-nos a abstrair essas contingências e a respeitar as pessoas como seres racionais, independentemente do que elas possa desejar em determinadasituação.”

Kant nos obriga a entender que o imperativo categórico, permanece no mundo abstrato ao da ciência, entretanto faz-se necessário entender que, para o individuo compreender o imperativo categórico, este precisa de uma estimulação sensorial, se recorrendo a ciência para tal, por isso Sandel (2013, p.161 explica com precisão:

Outra forma de abordar esse ponto é dizer que a moralidade não é empírica. Ela mantém certa distância do mundo. Ela faz um julgamento do mundo. A ciência não é capaz apesar de todo seu poder e discernimento de se ocupar das questões morais, porque atua no domínio do sensível.

Ora, a existência do imperativo categórico, não se dá por si só, sendo necessário a existência de algo perceptível, de uma experiência sensível, com o objeto sob análise da máxima da lei universal, nesse caso o objeto de análise é a inclusão. O querer da inclusão sob o aspecto do imperativo categórico só pode-se realizar se houver uma sensação cognitiva, que nas palavras de Telles Junior (1988, p. 195) é: 
A sensação cognitiva é sempre causada por impressão (modificação) em um órgão sensório, e consiste na percepção de uma qualidade sensível de um objeto (uma cor, um som, um gosto, etc.).

A máxima de Kant do imperativo categórico, só pode existir se existir uma sensação cognitiva, ou seja, uma ação pedagógica no sentido de demonstrar e se fazer conhecido o objeto do trabalho em questão. Logo se tem que o imperativo categórico não tem conteúdo epistemológico, como já dito, entretanto a inclusão é um fator puramente epistemológico quando avaliada sob a ética deKant.

A pedagogia conduz o caminho para a ética kantiana, quando propicia um juízo sobre os valores que são colocados a frente dos educandos, por meio do instrumento pedagógico. Quando Kant elucida a regra do imperativo categórico, que aqui é observada em sentido estrito o mesmo Kant, propõe que haja uma sistematização intelectual para se obter o imperativo categórico.

Referida sistematização só pode se dar por meio de um juízo racional, quando a sociedade compreende os direitos humanos, esta entende a a existência de dignidade em todos os seres humanos, pois houve compreensão e juízo valorativo sobre o objeto que foi repassado pedagogicamente, gerando condições de que haja no ambiente multicultural a alteridade entre os seressociais.

Logo alteridade, carece também de epistemologia, sendo apenas vontade ontológica do ser. Todavia, só se pode buscar a alteridade se houver a epistemologia de um objeto de conhecimento como meio para tal fim. Logo se vê que tanto alteridade como o imperativo categórico não são conceitos desprovidos de cientificidade, Mas sim, conceitos que necessitam buscar na ciência objeto de estudo para se perfazer no meio social.

Pode-se denotar que, a existência do imperativo categórico necessita do dasein, a busca do ser-o-aí de Heidegger tema que já foi estudado em tópico anterior, entretanto, não há como se fazer um juízo racional, sem entender o porquê desse juízo, logo tem-se que, o imperativo categórico só existe se existir a razão comunicativa possibilitando o dasein.

Ressalta-se que a formação da lei universal, que embasa o imperativo categórico, deve ser adstrita à autonomia do ser que elabora esta lei, pois ele age com liberdade para propor de acordo com o seu entendimento de mundo a sua lei moral. Por isso Sandel (2013, p. 156) afirma com precisão "Só agimos livremente quando agimos de acordo com o imperativo categórico."

É reconhecendo a cognoscência do objeto que é apresentado pedagogicamente que o educando pode fundamentar suas relações humanas de acordo com o imperativo categórico que ele mesmo criar, revelando uma relação de autonomia e afirmação da sua dignidade e da dignidade dos demais cidadãos. Por isso Sandel (2013, p. 160 leciona:

Como um ser natural, pertenço ao mundo sensível. Minhas ações são determinadas pela lei da natureza e pelas regularidades de causa e efeito. Esse é o aspecto da ação humana que a física, a biologia e a neurociência conseguem descrever. Como um ser racional, habita um 
mundo inteligível. Assim, independo das leis da natureza, sou autônomo, capaz de agir de acordo com uma lei que decreto para mim mesmo.

Pode-se concluir, em primeiro momento que o imperativo categórico carece de caráter cientifico, mas pode ser auxiliado pela pedagogia, na busca de garantir a inclusão e o respeito da sociedade para a pessoa com deficiência, e consequentemente a participação democrática dessas pessoas na sociedade, objetivando a efetividade de seus direitos fundamentais.

Deve-se perceber também que o imperativo categórico só pode surgir dentro de uma sociedade multicultural com abertura e sensibilidade para entender as diferenças existentes no meio social. Denota-se que o imperativo categórico só pode existir associado à razão comunicativa de Habermas, e tal assertiva só pode ser verdadeira, se for utilizada a interação pedagógica com os direitos humanos na função de propiciar aos educandos o conhecimento das diferenças.

\section{CONCLUSÃO}

Dentro do que foi exposto, evidenciou-se que os direitos fundamentais das pessoas com deficiência, só podem ser respeitados se houver no meio social um reconhecer da deficiência como uma das múltiplas formas de vida existentes, com o objetivo de se formar com a sociedade brasileira um multiculturalismo.

Neste aspecto a rede ágrafa de Habermas torna-se de suma importância, pois dentro dela pode-se produzir alteridade e o reconhecimento da dignidade do outro, e portanto o respeito desta. Sendo a partir deste momento do reconhecimento que surge o desenvolvimento dos princípios constitucionais como a igualdade, a fraternidade e a solidariedade.

Foi defendido também que à parte da educação, pode ser buscado o imperativo categórico de Kant, com intuito de formar uma sociedade que respeite a diferença, garanta o agir comunicativo e propicie a participação democrática de todos os cidadãos, não obstante a educação vira um instrumento de formação desta ética, tendo em vista as operações filosóficas dos direitos fundamentais.

Essas operações filosóficas que é o sein, sollen, que precisa ser complementado pelo deasein, permite o reconhecimento do dever de respeito existente nos direitos fundamentais da pessoa com deficiência por toda a sociedade, fomentando contudo, uma sociedade em que haja o imperativo categórico fazendo que os seus cidadãos busquem sempre por mais justiça social. 


\title{
THE INCLUSION OF THE DISABLED PERSON AND THE MULTIC ULTURALISM: THE CONSTRUCTION OF A MORE SOLIDARY COUNTRY
}

\begin{abstract}
This article aims to study the inclusion of disabled person under the bias of multiculturalism, that seek to bias shows how to design the fundamental rights of this population, with a view to forming a social ethic that allows respect for the disabled, and consequently guarantees the effectiveness of their citizenship. Meanwhile, fosters the creation of a ágrafa network, based on a communicative action which has the aim of instilling in society solidarity between citizens providing a sensitivity to differences, and therefore with the deficiencies. This study was done based on an inductive methodology-bibliography.
\end{abstract}

Keywords: Person with disabilities; Ethics; ágrafa network; Kant; multiculturalism.

\section{REFERENCIAS}

ALEXY, Robert. Teoria dos direitos fundamentais. São Paulo, Malheiros, 2012.

COMPARATO, Fabio Konder. Afirmação histórica dos direitos humanos. São Paulo: Saraiva,2010.

CRUZ, Álvaro Ricardo de Souza. O direito à diferença: as ações afirmativas como mecanismo de inclusão social de mulheres, negros, homossexuais e portadores de deficiência. Belo Horizonte: Del Rey, 3a ed, 2009.

ENGELMANN, Wilson. Direito Natural, Ética e Hermenêutica. Livraria do Advogado Editora, 2007.

FREIRE, Paulo; FREIRE, Ana Maria Araujo (orgs). Pedagogia dos Sonhos Possíveis. 3a reimpressão. São Paulo. Editora Unesp. 2001.

GIACÓIA, Oswaldo Jr. Heidegger Urgente introdução a um novo pensar. São Paulo: Três Estrelas, 2013.

HABERMAS, Jürgen, A inclusão do outro: estudos de teoria política. 3. ed. São Paulo. Loyola. 2007.

Direito e democracia: entre facticidade e validade. Rio de Janeiro: Tempo Brasileiro, v. 1, 1997.

HESSE, Konrad; MENDES, Gilmar Ferreira. A força normativa da Constituição. SA Fabris Editor, 1991.

JABORANDY, Clara Cardoso Machado. A Implementação de Politicas Publicas á Luz do Constitucionalismo Fraterno. In: Munir Cury e outros (org). Fraternidade Como Categoria Jurídica. São Paulo. Cidade Nova. 2013. p. $81-98$

KANT, Immanuel. Fundamentação da metafísica dos costumes. Lisboa: 70, 1984. (Textos Filosóficos7).

LORENZO, Wambert Gomes Di. Teoria do estado de solidariedade: da dignidade da pessoa humana aos seus princípios corolários. São Paulo. Elsevier.2010.

PADILHA, Paulo Roberto. Educação em direitos humanos sob a ótica dos ensinamentos de Paulo Freire. Múltiplas Leituras, v. 1, n. 2, p. 23-35,2009. 
SANDEL, Michael J.Justiça. Oque é Fazer a Coisa Certa. 6a edição. Rio de Janeiro: Civilização Brasileira, 2012.

TELLES JUNIOR, Goffredo. Ética do mundo da célula ao mundo da cultura. Rio de Janeiro: Forense, 1988. Iniciação na ciência do direito. São Paulo; Saraiva, 2008.

Trabalhoenviadoem 11 deagosto de 2015.

Aceitoem04denovembrode2015. 